\title{
Investigation of Seiche Oscillations in a Free Entrance Bay
}

\author{
Yu. V. Manilyuk*, L. V. Cherkesov
}

\author{
Marine Hydrophysical Institute, Russian Academy of Sciences, Sevastopol, Russian Federation
} *e-mail: uvmsev@yandex.ru

\begin{abstract}
Seiche oscillations in a free entrance bay are investigated within the framework of the linear theory of long waves in two-dimensional formulation. Analytical solution for a rectangular basin of constant depth for the case when the nodal line of the level is located at the basin entrance is obtained. It is shown that allowance for two-dimensional spatial character is important for transverse seiches: the wave currents depend on two spatial coordinates, and their amplitudes are the functions of the basin width and length. The amplitudes of wave current velocities are the functions of the basin width and length for transversal seiches and are directly proportional to the initial level deviations as well as inversely proportional to square root of the basin depth. It is found that for the longitudinal seiches the wave current velocities are normal to the bay entrance and their maximum values do not depend on its width and length. The longitudinal seiches are characterized by the highest velocities of the wave currents. The features of the seiches in a free entrance basin and in a completely enclosed one are compared, their similarities and differences are determined. The lowest seiche mode in the basin with a free entrance is the Helmholtz mode. It is absent in an enclosed basin and also this mode has no nodal lines within the bay. Wave current for the Helmholtz mode is always directed perpendicularly to the basin entrance and its maximum velocity does not depend on the basin width and length. It is directly proportional to free surface initial deviation and inversely proportional to square root of the basin depth. The lowest current velocities will take place at an open boundary of the basin. The estimates for seiche oscillation periods and wave current velocities approximating the Kruglaya Bay in Sevastopol are obtained.
\end{abstract}

Keywords: seiches in a bay, free waves, long waves, wave flows, Helmgoltz mode, analytic solutions.

DOI: 10.22449/1573-160X-2017-4-16-25

(C) 2017, Yu. V. Manilyuk, L. V. Cherkesov

(C) 2017, Physical Oceanography

Introduction. Most of the seas on the Earth have bays which are used for various purposes: for the construction of ports, beaches and other infrastructure. Therefore, the study of dynamic processes in the bays is of great practical value. Seiches, which are observed both in the basins in general and in certain bays, are one of the common phenomena in the enclosed basins. In the bays seiches cause certain inconveniences and sometimes they are even hazardous for navigation. Such phenomenon as harbor seiche [1, 2] is often associated with these hazards. Harbor seiche is a periodic water mass movement directed from one side to another. At the same time, anchored and docked ships make rhythmic motions in time with water movement and can break adrift, break the moorings, break their sides against mooring walls, crash into each other suffering significant damage [1, 2].

Seishes in the bays constantly attract the attention of the researchers. Resonance in the harbor is considered in [2, 3], in [2] a bibliography of foreign authors on this issue is also given. In [4-7] the results of the processing of seiche field observations and numerical calculations for bays and gulfs of the Far East are analyzed. In $[8,9]$ the results of seiche observational data and numerical simulation processing in Sevastopol Bay are given. In [10] resonant amplification of seiche oscillations in the estuary is considered. 
In some cases, the problem of seiches in the bay allows for an analytical solution. In particular, in $[2,11,12]$ for the simple shape bays the formulas for calculating the periods of the seiche modes depending on one spatial coordinate are given. Experiments show that it is important to take into account two-dimensionality of wave process. Thus, in [13] free waves are studied in a closed rectangular channel of variable cross-section using a laboratory experiment and numerical calculations. It is determined that one-dimensional model provides satisfactory description of the seiche oscillation frequencies. However, the data of such model on the position of seiche oscillation nodal points differ from the data obtained with the help of the two-dimensional model and the experiment results. A significant difference in oscillation amplitude dependence on the longitudinal coordinate obtained from onedimensional and two-dimensional models also takes place. Therefore, it is of interest to find an analytical solution for seiche problem in a bay in a two-dimensional formulation.

The aim of the given paper is to obtain an analytical solution (depending on two spatial coordinates) for seiche oscillation problem for rectangular shape bay with free entrance, which is equal to its width, and constant depth. The obtained analytical solution is applied for assessing seiche parameters in the model basin which approximates the Kruglaya Bay situated within Sevastopol limits.

Problem statement and obtaining an analytical solution. Consider free linear oscillations of homogeneous non-viscous liquid in a bay with one free boundary. We will assume that the waves are long and atmospheric pressure over the water area is constant. The influence of the Earth's rotation is neglected. In this case, the motion of liquid is described by the system of equations of long waves [14]

$$
u_{t}=-g \zeta_{x}, v_{t}=-g \zeta_{y}, \zeta_{t}=-(h u)_{x}-(h v)_{y},
$$

where $x, y$ are Cartesian coordinates; $u, v$ are the projections of liquid movement velocity vector on $x, y$ axis, respectively; $\zeta$ is a free surface deviation; $h$ is a depth of a basin; $t$ is time; $g$ is the free fall acceleration.

Impermeability condition must be satisfied on the rigid sidewalls of the basin

$$
V_{n}=0 \text {, }
$$

here $V_{n}$ is the velocity component normal to the sidewall of the basin. On the free boundary of the basin the satisfaction of free passage condition is required (normal derivative of normal velocity component to the liquid basin boundary is equal to zero):

$$
\left.\frac{\partial V_{n}}{\partial n}\right|_{x=a}=0 .
$$

Consider the bay of rectangular shape with constant depth $h$ (Fig. 1). The bay length is $a$ and the width is $b$. The width of the bay entrance is also equal to $b$. With regard to this, boundary condition (2) will take the following form

$$
u(0, y)=0, \quad v(x, 0)=0, \quad v(x, b)=0,
$$


boundary condition (3) will be written down as

$$
\left.\frac{\partial u}{\partial x}\right|_{x=a}=0
$$

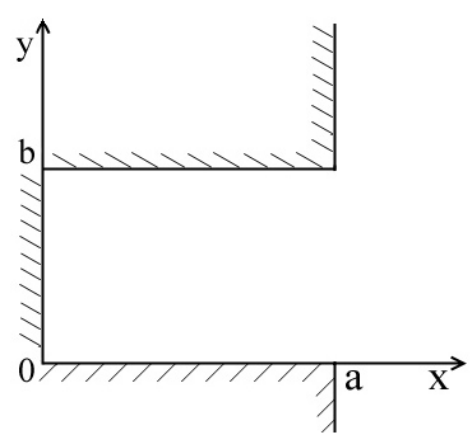

Fig. 1. Model basin

We will a solution for system (1) in a form of functions which are periodic by the time and which satisfy the boundary conditions (4), (5):

$$
\begin{gathered}
u_{k m}(x, y, t)=\bar{u}_{k m}(y) \sin \left((1+2 k) \pi x(2 a)^{-1}\right) \sin \sigma_{k m} t, \\
v_{k m}(x, y, t)=\bar{v}_{k m}(x) \sin \left(m \pi y b^{-1}\right) \sin \sigma_{k m}, \\
\zeta_{k m}(x, y, t)=\bar{\zeta}_{k m}(x, y) \cos \sigma_{k m} t,
\end{gathered}
$$

where $\sigma_{k m}$ is a frequency of liquid oscillations, $k=0,1,2, \ldots, \quad m=0,1,2, \ldots$, . Substituting (6) into (1), we obtain

$$
\begin{gathered}
\frac{\partial \bar{\zeta}_{k m}(x, y)}{\partial x}=-\frac{\sigma_{k m}}{g} \bar{u}_{k m}(y) \sin \left[\frac{(1+2 k) \pi x}{2 a}\right], \\
\frac{\partial \bar{\zeta}_{k m}(x, y)}{\partial y}=-\frac{\sigma_{k m}}{g} \bar{v}_{k m}(x) \sin \frac{m \pi y}{b} .
\end{gathered}
$$

Integrating the equation (7) over $x$ and (8) - over $y$, we will find

$$
\begin{gathered}
\bar{\zeta}_{k m}(x, y)=\frac{2 \sigma_{k m} a}{g(1+2 k) \pi} \bar{u}_{k m}(y) \cos \frac{(1+2 k) \pi x}{2 a}, \\
\bar{\zeta}_{k m}(x, y)=\frac{\sigma_{k m} b}{g m \pi} \bar{v}_{k m}(x) \cos \frac{m \pi y}{b} .
\end{gathered}
$$

We will seek for $\bar{u}_{k m}(y)$ and $\bar{v}_{k m}(x)$ in the following form:

$$
\bar{u}_{k m}(y)=u_{0 k m} \cos \left(m \pi y b^{-1}\right), \bar{v}_{k m}(x)=v_{0 k m} \cos \left((1+2 k) \pi x(2 a)^{-1}\right),
$$

here $u_{0 k m}, v_{0 k m}$ are the amplitudes of velocity components. 
Equating right and left parts of equations (9), (10) to each other and replacing $\bar{u}_{k m}(y)$ and $\bar{v}_{k m}(x)$ by the expressions from (11) we will find the relation between the amplitudes of velocity components:

$$
v_{0 k m}=\frac{2 a m}{b(1+2 k)} u_{0 k m} .
$$

From the third equation of system (1), taking into account (6), (9), (10), (11), we obtain expressions for calculating the frequencies and periods of seiche oscillations of liquid in a rectangular-shaped bay of constant depth:

$$
\begin{gathered}
\sigma_{k m}=\frac{\pi}{2 a b} \sqrt{g h} \sqrt{(1+2 k)^{2} b^{2}+4 m^{2} a^{2}}, \\
\tau_{k m}=\frac{4}{\sqrt{g h}} \frac{a b}{\sqrt{(1+2 \mathrm{k})^{2} b^{2}+4 m^{2} a^{2}}} .
\end{gathered}
$$

Taking into account (9), (11) formula (6) will take the form

$$
\zeta_{k m}(x, y, t)=\frac{2 \sigma_{k m} a}{g(1+2 k) \pi} u_{0 k m} \cos \frac{(1+2 k) \pi x}{2 a} \cos \frac{m \pi y}{b} \cos \sigma_{k m} t .
$$

Expression (15) can be written as follows:

$$
\zeta_{k m}(x, y, t)=\zeta_{0 k m} \cos \frac{(1+2 k) \pi x}{2 a} \cos \frac{m \pi y}{b} \cos \sigma_{k m} t,
$$

where $\zeta_{0 \mathrm{~km}}$ is an amplitude of free surface deviation. Formula (16) allows one to find a profile of liquid free surface for the specified values $k, m, \zeta_{0 \mathrm{~km}}$ and $a, b$ geometric parameters of the basin.

Using (15) and (16), we obtain

$$
\zeta_{0 k m}=\frac{2 \sigma_{k m} a}{g(1+2 k) \pi} u_{0 k m} .
$$

Taking into account expression (13), the relation (17) takes the form

$$
\zeta_{0 k m}=\frac{u_{0 k m}}{(1+2 k) b} \sqrt{\frac{h}{g}} \sqrt{(1+2 k)^{2} b^{2}+4 a^{2} m^{2}} .
$$

From here we have a formula for calculating $u_{0 k m}$ values by a specified value $\zeta_{0 k m}$ :

$$
u_{0 k m}=\zeta_{0 k m} \sqrt{\frac{g}{h}} \frac{(1+2 k) b}{\sqrt{(1+2 k)^{2} b^{2}+4 m^{2} a^{2}}} .
$$

Substituting the expression (19) into (12), we obtain the formula for calculating $v_{0 k m}$ by the specified value $\zeta_{0 k m}$ :

$$
v_{0 k m}=\zeta_{0 k m} \sqrt{\frac{g}{h}} \frac{2 m a}{\sqrt{(1+2 k)^{2} b^{2}+4 m^{2} a^{2}}} .
$$


Using (6), (11), (19), (20), we write out the formulas for calculating the components of wave velocities:

$$
\begin{aligned}
& u_{k m}(x, y, t)=\zeta_{0 k m} \sqrt{\frac{g}{h}} \frac{(1+2 k) b}{\sqrt{(1+2 k)^{2} b^{2}+4 m^{2} a^{2}}} \sin \frac{(1+2 k) \pi x}{2 a} \cos \frac{m \pi y}{b} \sin \sigma_{k m} t, \\
& v_{k m}(x, y, t)=\zeta_{0 k m} \sqrt{\frac{g}{h}} \frac{2 m a}{\sqrt{(1+2 k)^{2} b^{2}+4 m^{2} a^{2}}} \cos \frac{(1+2 k) \pi x}{2 a} \sin \frac{m \pi y}{b} \sin \sigma_{k m} t .
\end{aligned}
$$

Thus, for rectangular bay of constant depth with a free entrance (its width is equal to the depth of the bay) the solution for the system of equations of long waves is obtained. It allows one to find the periods of seiche oscillation modes according to formula (14) and, specifying the initial values of $\zeta_{0 \mathrm{~km}}$ free surface deviation amplitudes, to calculate free surface deviations on the basis of relation (16), as well as wave velocities of corresponding modes using expressions (21), (22).

We analyze the maximum velocities of wave currents caused by seiches. For the longitudinal seiches $(k \neq 0, m=0)$ from the formula (20) it follows that $v_{0}=0$. This mean that wave currents are always directed in parallel with $x$ axis. From the expression (19), taking into account the fact that $(k \neq 0, m=0)$, we will find

$$
u_{0 k 0}=\zeta_{0 k 0} \sqrt{\frac{g}{h}} .
$$

It follows from (23) that the maximum velocity of wave current for longitudinal seiches depends neither on the basin width $b$, nor on its length $a$. It is directly proportional to the amplitude of initial free surface deviation and inversely proportional to $\sqrt{h}$. Similar regularity takes place for the case when the basin is completely enclosed [15].

For transverse seiche $(k=0, m \neq 0)$ from the formula (19) we obtain

$$
u_{00 m}=\zeta_{00 m} \sqrt{\frac{g}{h}} \frac{b}{\sqrt{b^{2}+4 m^{2} a^{2}}}
$$

and using (20) we will find

$$
v_{00 m}=\zeta_{00 m} \sqrt{\frac{g}{h}} \frac{2 m a}{\sqrt{b^{2}+4 m^{2} a^{2}}} .
$$

On the basis of expressions (24), (25) we conclude that $u, v$ amplitudes are not equal to zero. It follows that in the bay the wave currents of transverse seiches are not parallel to the axis $y$. At that, $u_{0}, v_{0}$ are inversely proportional to $\sqrt{h\left(b^{2}+4 m^{2} a^{2}\right)}, u_{0}$ is directly proportional to $b, v_{0}$ is directly proportional to $a$. This significantly distinguishes the seiches in a bay from the ones in completely enclosed basin, for which $u_{0}=0, v_{0}$ is determined by the formula similar to (23) [15]. If the bay length $b$ is much greater than its width $a$, then $u_{0}$ will tend to 
$\zeta_{00 m} \sqrt{\frac{g}{h}}, v_{0}-$ to $\zeta_{00 m} \sqrt{\frac{g}{h}} \frac{2 m a}{b}$. In the case when $a>>b$, amplitude $u_{0}$ will tend to $\zeta_{00 m} \sqrt{\frac{g}{h}} \frac{2 m a}{b}, v_{0}-$ to $\zeta_{00 m} \sqrt{\frac{g}{h}}$.

For longitudinal-transverse seiches $(k \neq 0, m \neq 0)$ from the expressions (19), (20) it follows that the amplitudes $u, v$ depend on $a, b, h$.

For the Helmholtz mode ( $k=0, m=0)$ from the formula (20) we obtain that $v_{0}=0$. On the basis of the equation (19), we find that $u_{0}$ is determined by the formula (23). It follows that the wave current for the Helmholtz mode is always directed in parallel with $x$ axis and its maximum velocity depends neither on the basin width, nor on its length. It is always directly proportional to the amplitude of initial free surface deviation and is inversely proportional to $\sqrt{h}$. Note that the Helmholtz mode is absent in a completely enclosed basin.

The following regularity is valid for all types of seiches in the bay: the greater the depth of the bay, the lower is the maximum velocity of wave currents caused by the seiches.

The calculation of seiche parameters in the model basin, approximating the Kruglaya Bay, is performed on the basis of the analytical solution obtained in this paper. The city beach "Omega", a yacht club and other objects are situated on the shores of this bay. When carrying out the calculations, the bay was approximated by a rectangular basin with $2.5 \mathrm{~m}$ constant depth, $1200 \mathrm{~m}$ length, $800 \mathrm{~m}$ width, initial level elevation amplitude $\zeta_{0}$ was assumed to be $20 \mathrm{~cm}$.

The periods of first nine seiche modes in the model basin calculated by the formula (14) are given in the Table.

Seiche periods and the maximum values of wave current velocity modulus in the model basin approximating the Kruglaya Bay

\begin{tabular}{c|c|c|c|c}
\hline Mode number & $k$ & $m$ & Period, min & $\left|\mathbf{V}_{k m}\right|^{\max }, \mathrm{m} / \mathrm{s}$ \\
\hline 1 & 0 & 0 & 16.2 & 0.40 \\
2 & 1 & 0 & 5.4 & 0.40 \\
3 & 0 & 1 & 5.1 & 0.38 \\
4 & 1 & 1 & 3.8 & 0.28 \\
5 & 2 & 0 & 3.2 & 0.40 \\
6 & 2 & 1 & 2.8 & 0.34 \\
7 & 0 & 2 & 2.7 & 0.39 \\
8 & 1 & 2 & 2.4 & 0.35 \\
9 & 2 & 2 & 2.1 & 0.30 \\
\hline
\end{tabular}

As it can be seen from the Table, the Helmholtz mode period makes up $16.2 \mathrm{~min}$. It is three times larger than the periods of modes of single-node longitudinal and transverse seiches which are equal to 5.4 and 5.1, respectively.

Consider the oscillations of the level. As is obvious from the formula (16), the consequence of satisfying the condition (5) of free passage of waves at the open 
boundary of the basin is the fact that the nodal line of the level for all seiche modes is located at the exit from the bay. The areas, in which level deviations are maximal by the modulus, will always take place on the wall $(0, y)$ at that.

As the analysis of level isolines has shown, in the bay the nodal lines, which are parallel to the axis $y$, are shifted towards the apex of the basin (in comparison to the nodal lines in a completely enclosed basin). The position of nodal lines which are parallel to the axis $x$ does not change. As an example, the isolines of level mode $(k=2, m=2)$ at $t=0$ are shown in Fig. 2, $a$. The pattern of level isolines for this mode in the enclosed basin is given in [16]. Level isolines of singlenode transversal seiche $(k=0, m=1)$ at $t=0$ are represented in Fig. 2, $b$. As is obvious from this figure, with the distance from the wall $(0, y)$ the violation of isolines parallelism takes place and they curve towards the walls $(x, 0),(x, b)$. In the completely enclosed basin level isolines of this mode are always parallel to the axis $x$.
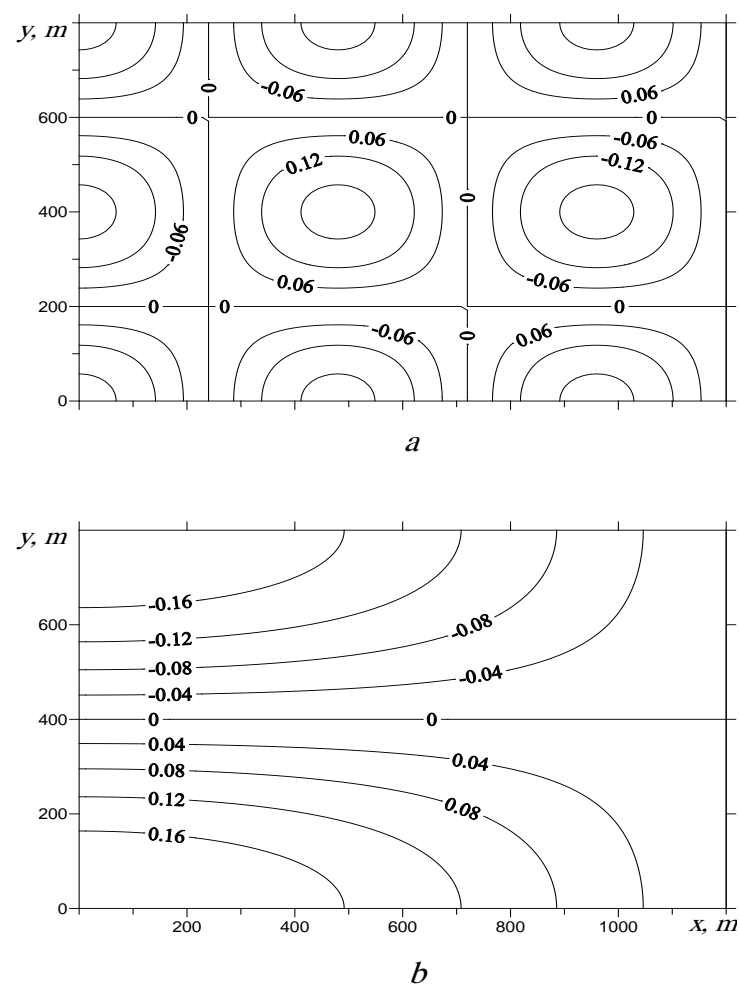

Fig. 2. Isolines of liquid level in the basin: $a-(k=2, m=2)$ mode; $b-(k=1, m=0)$ mode

Consider the features of wave currents. As illustrated above, for the transversal seiches in the bay the velocity of wave seiche currents depends on two spatial coordinates. This fact differs them from the wave currents in the enclosed basin where they are in parallel to the axis $y$. In Fig. 3, $a$ a vector field of wave current velocity for $(k=1, m=0)$ mode in the moment of time when $\sin \sigma_{10} t=1$ is shown. It can be seen that in the bay part situated below the nodal line, which pass- 
es through the point $(0, b / 2)$ in parallel with the axis $x$, a current directed towards the bay exit is formed. In the opposite part of the bay the current directed from the bay entrance is formed. The directions of the currents will change to the opposite ones every half-period of the wave at that. The currents are the most intensive in that part of the bay which is closer to the bay entrance.

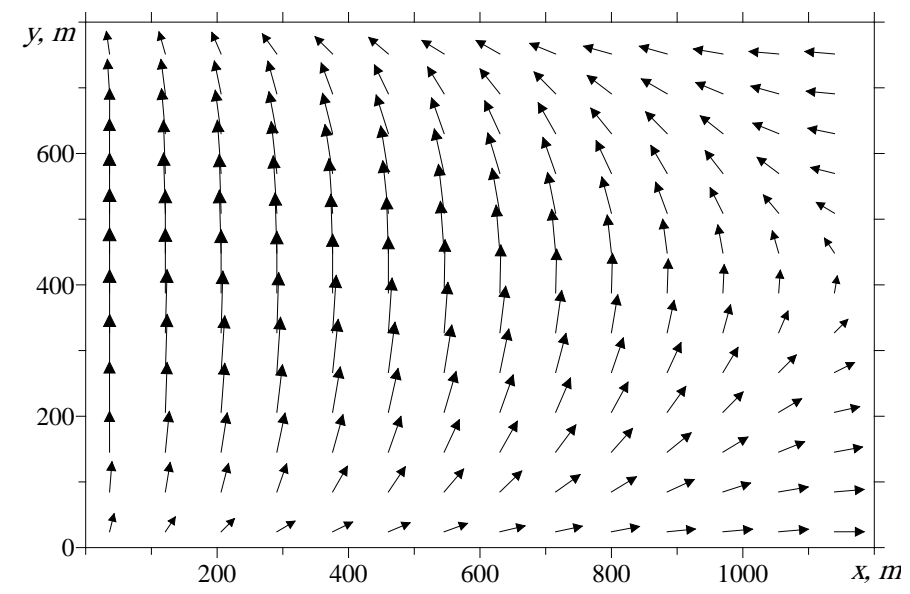

Fig. 3. Vector field of wave current velocity for $(k=1, m=0)$ mode

In conclusion, we are to consider in more detail that the Helmholtz mode, which is absent in completely enclosed basin. In foreign literature it is often called "pumping mode". This is due to the fact that the given mode operates like a pump. In the first half of the period the liquid is "pumped out" from the bay, while the level in the vicinity of the wall $(0, y)$, which is located against the bay entrance, decreases. In the second part of the period the liquid is "pumped into" the bay and the level near this wall increases. As is shown above, the fluid flows in parallel to the axis $x$ and the maximum velocity of this process makes up $40 \mathrm{~cm} / \mathrm{s}$ (if the maximum of level deviation is $20 \mathrm{~cm}$ ).

The maximum values of wave current velocity modulus for the first nine seiche modes in the model basin at the initial level elevation equal to $20 \mathrm{~cm}$ are represented in the Table. It can be seen that the longitudinal seiches have the maximum velocities of currents (equal to $40 \mathrm{~cm} / \mathrm{s}$ ).

Conclusions. It is determined that seiche oscillations in the bays with free entrance significantly differ from the ones in completely enclosed basins.

1. The spectrum of self-oscillations of the bay contains the mode which is absent in a completely enclosed basin. This mode, which is called the Helmholtz mode, has no nodal lines within the basin. Wave current is directed perpendicularly to the bay entrance and its maximum velocity does not depend on the bay width and length (it is inversely proportional to the square root of the bay depth).

2. Wave currents of transverse seiches in the bay (their nodal lines are perpendicular to the entrance to the bay) depend on two spatial coordinates. The amplitudes of their velocities are the functions of width and length of the basin at that. 
3. For the longitudinal seiches (their nodal lines are parallel to the bay entrance), the velocities of the currents are perpendicular to the bay entrance and their maximum values do not depend on its width and length. They are determined by the bay depth and the amplitude of the initial level deviation.

4. Longitudinal seiches have the highest velocities of wave currents.

Acknowledgements. The work was carried out within the framework the state order No. 0827-2014-0010 “Complex Interdisciplinary Studies of Oceanographic Processes Determining the Functioning and Evolution of the Black and Azov Sea Ecosystem on the Basis of Modern Methods of Control of the Marine Environment and Gridtechnology".

\section{REFERENCES}

1. Labzovskiy, N.A., 1971. Neperiodicheskie Kolebaniya Urovnya Morey [Non-Periodic Sea Level Fluctuations]. Leningrad: Gidrometeorologicheskoe izdatelstvo, 238 p. (in Russian).

2. Rabinovich, A.B., 2010. Seiches and Harbor Oscillations (Chapter 9). In: Y.C. Kim, 2010. Handbook of Coastal and Ocean Engineering. Singapoure: World Scientific Publ., pp. 193236. Available at: https://ru.scribd.com/doc/175952645/Handbook-of-Coastal-and-OceanEnginee-ring-Y-Kim-World-2010-WW [Accessed 11 July 2017].

3. Ippen, A.T. ed., 1966. Estuary and Coastline Hydrodynamics. New York: McGraw-Hill Book Co, 761 p.

4. Kovalev, P.D. and Kovalev, D.P., 2013. Osobennosti Seyshevykh Kolebaniy v Zalivakh i Bukhtakh Dal'nego Vostoka: Primor'ya, Sakhalina, Yuzhnykh Kuril'skikh Ostrovov [Seiche Vibrations Features in Bays and Inlets of Far East: Pri-Morye, Sakhalin, Southern Kuril Islands]. Vestnik Tambovskogo Universiteta [Tambov University Reports], 18(4-1), pp. 13771382. Available at: https://elibrary.ru/item.asp?id=19058861 [Accessed 11 July 2017] (in Russian).

5. Zheleznyak, M.I., Kantarzhi, I.G., Sorokin, M.V. and Polyakov, A.I., 2015. Rezonansnye Kharakteristiki Akvatoriy Morskikh Portov [Resonance Characteristics of Sea Ports]. Inzhenerno-Stroitel'nyy Zhurnal, [e-journal] (5), pp. 3-19. doi:10.5862/MCE.57.1 (in Russian).

6. Kovalev, D.P., 2012. Yavleniya Tyaguna v Portakh Sakhalina [Harbor Seiche in the Ports of Sakhalin]. Mir Transporta, [e-journal] 10(6), pp. 36-43. Available at: https://elibrary.ru/item.asp?id=18268062 [Accessed 01 June 2016] (in Russian).

7. Dolgikh, G.I., Budrin, S.S., Dolgikh, S.G., Chupin, V.A., Shvets, V.A. and Yakovenko, S.V., 2016. Free Oscillations of Water Level in the Posyet Gulf Bays (the Sea of Japan). Russian Meteorology and Hydrology, [e-journal] 41(8), pp. 559-563. doi:10.3103/S1068373916080057

8. Goryachkin, Yu.N. and Ivanov, V.A., 2006. Uroven Chernogo Morya: Proshloe, Nastoyaschee i Buduschee [Level of the Black Sea: Past, Present and Future]. Sevastopol: ECOSIGidrofizika, 210 p. (in Russian).

9. Dotsenko, S.F. and Ivanov, V.A., 2014. Natural Hazards in the Sea of the Azov-Black Sea Region. Kyiv: Akademperiodyka, $190 \mathrm{p}$.

10. Zyryanov, V.N. and Chebanova, M.K., 2016. Hydrodynamic Effects at the Entry of Tidal Waves into Estuaries. Water Resources, [e-journal] 43(4), pp. 621-628. doi:10.1134/S0097807816040187

11. Chow, V.T. ed., 1972. Advances in Hydroscience. New York and London: Academic Press. Vol. 8, 359 p. Available at: http://www.sciencedirect.com/science/bookseries/00652768/8 [Accessed 11 July 2017].

12. Rabinovich, A.B., 1993. Dlinnye Gravitatsionnye Volny v Okeane: Zakhvat, Rezonans, Izluchenie [Long Gravity Waves in the Ocean: Capture, Resonance, Emission]. S.-Petersburg: Gidrometeoizdat, 325 p. (in Russian). 
13. Bukreev, V.I., Sturova, I.V. and Chebotnikov, A.V., 2013. Seiche Oscillations in a Rectangular Channel with an Abrupt Expansion of the Cross Section. J. Appl. Mech. Techn. Phys., [e-journal] 54(4), pp. 531-540. doi:10.1134/S0021894413040032

14. Sretenskiy, L.N., 1977. Teoriya Volnovyih Dvizheniy Zhidkosti [The Theory of Fluid Wave Motions]. Moscow: Nauka, 815 p. (in Russian).

15. Cherkesov, L.V. and Manilyuk, Yu.V., 2016. Svobodnyie Kolebaniya Zhidkosti v Ogranichennom Morskom Basseyne [Free Liquid Oscillations in a Bounded Marine Basin]. In: SSC RAS, 2016. Ekologiya, Ekonomika, Informatika. Sistemnyiy Analiz i Modelirovanie Ekonomicheskikh i Ekologicheskikh Sistem [Ecology. Economy. Informatics. System Analysis and Mathematical Modeling of Ecological and Economic Systems]. Rostov-on-Don: Southern Scientific Center of RAS Publishers. Vol. 2, pp. 678-689 (in Russian).

16. Kochin, N.E., Kibel, I.A. and Roze, N.V., 1956. Teoreticheskaya Gidromekhanika [Theoretical Hydromechanics]. Moscow: Gostekhizdat. Vol. 1, 560 p. (in Russian). 